\title{
INTERCULTURAL INTERACTIONS IN A MILITARY CONTEXT
}

\author{
Valentina GEORGIEVA \\ “G. S. Rakovsky” National Defence College, Sofia, Bulgaria \\ valgeorgieva@yahoo.com \\ Petar MARINOV \\ “G. S. Rakovsky” National Defence College, Sofia, Bulgaria \\ petyr.marinov@abv.bg
}

\begin{abstract}
The article focuses on the impact of various factors on the process of communication between military specialists and with the local civilians during peace support operations. The importance of religion, national and ethnic identities, military subculture, social status, and personal characteristics for achieving success or failure in interactions is underlined. Some differences between civil culture and military culture are disclosed and the need for cultural knowledge of the military members is stressed. The study is based on presenting and analysing situations of current intercultural interactions in Afghanistan, which deal with various problems that could be encountered by servicemen on a daily basis, i.e. body language differences, expression of friendly, unfriendly or indifferent attitude, typical reactions to gestures, common everyday topics for informal chats. Although the cultural interactions take place in present-day Afghanistan, the conclusions and suggestions are applicable to a much wider context of interacting between people with different cultural background.
\end{abstract}

KEYWORDS: culture, military, intercultural communication, peace support operations, interaction

1. Introduction

Afghanistan, present days: international peacekeepers work together with the servicemen of the newlyestablished National Afghan Army. Is it possible? Can former enemies from opposing cultures and religions cooperate? How do they communicate and socialize?

A description of typical everyday interactions between military members from different cultural worlds could be the following:
It is 10 o'clock in the morning and 30 recruits from the National Afghan Army are having their scheduled lesson in Religious Education as part of their basic military training. All of them, dressed in new military uniforms, sit on the floor in a circle. Their lecturer, mullah Ahmed, is going to explain Muslim husband's obligations when a Bulgarian officer, a member of the Operational Mentoring and Liaison Team (OMLT) whose duties include facilitating military training of the Afghans 
with whatever military expertise needed, enters the 'classroom', followed by his interpreter. The lesson is interrupted immediately by the mullah: he gives an order to the nearest Afghan private to bring two chairs for the visitors and invites the visitors to sit on the chairs and to join the class. However, the advisor decides to politely refuse to sit on a chair and asks for permission to join the circle of the Afghan soldiers.

What would you personally do if you had to perform your professional duties (no matter what your occupation is) in completely unfamiliar surroundings with people who do not speak your language, do not share your religion, your social and political views or your free-time activities? Would you be able to communicate professionally or personally with them? The answers to the above questions are positive only when the awareness that cultural differences do exist and that people do share the identity and behavior of each member of the society becomes part of professional and personal ethics.

This article is based on personal experience narrated in short stories, followed by analysis and explanations. The aim is to present various aspects of interactions between military specialists, as well as between the military and civilians, from different cultures in today's Afghanistan, but the conclusions and suggestions are applicable to a much wider context of interacting between people with different professional, social, religious and cultural background.

\section{Intercultural Communication in a Military Context}

When discussing the various aspects of communication in a military context, the following considerations should be taken into account:

$>$ Military (sub)culture;

$>$ National/ethnic identities;

> Social systems/circumstances;
Religious beliefs and differences;

$>$ Personal characteristics.

All of the above factors and many more affect the process of intercultural communication (IC) between people from different cultures occurring "whenever a message produced in one culture must be processed in another culture" (Porter \& Samovar 1994).

If we try to analyze the situation at the beginning of the article from the point of view of IC and the cultural messages it contains, we will have to pay attention to numerous details which differ in the military cultures of the participants in this story: Afghan culture of the bigger number of the participants in this particular situation on the one hand, and Bulgarian culture of the supervisor, on the other. Will both sides in this interaction be able to get their message across and process the message of the other party? When the mullah orders chairs for the newcomers, his message is: "You are different. You are not Muslim, you are a supervisor here, you have the highest rank here, so you need a chair to sit on". What is the right way to behave: to behave as you are expected to behave, i.e. to stick to your own way of doing things back in your military surroundings, or to act as a member of the majority (i.e. as an Afghan) and to try to actively cooperate with their community? These are possible questions to be dealt with in a similar situation and the Bulgarian officer had to take the decision as quickly as possible: in case he decided to behave the way he behaves in his usual professional environment, he had to adhere to the assigned role of a supervisor, to become a passive observant of what was going on in the classroom during the religious lesson and to keep the power distance. His response was different, however, and the immediate consequence was that he gained the trust and respect of all the participants on the spot, which in turn led to establishing friendly working relations with his Afghan partner. 
The importance of considering the above factors and learning as much as possible about the people you are going to interact with is implicitly stressed in the conclusions of the Russian General Staff (2002) about the Soviet-Afghan War: "When the highest political leaders of the USSR sent its forces into this war, they did not consider the historic, religious, and national particularities of Afghanistan. It is now clear that the Afghans, whose history includes many centuries of warfare with various warring groups, could not see these armed strangers as anything but armed invaders. And since these strangers were not Muslim, a religious factor was added to the national enmity".

Intercultural communication in a military context is a much broader concept than a term-derivative of the NATO's term of culture in "NATO Glossary of Terms and Definitions" (2013) with its definition from 1974 as "a feature of the terrain that has been constructed by man. Included are such items as roads, buildings, and canals; boundary lines; and, in a broad sense, all names and legends on a map." This is a very narrow and imprecise definition of 'culture' which has been re-defined by the US Army's Training and Doctrine Command Culture Center as a "dynamic social system", containing the values, beliefs, behaviors, and norms of a "specific group, organization, society or other collectivity" learned, shared, internalized, and changeable by all members of the society in order to facilitate the military in their intercultural interactions" (Watson, 2010).

The article is not aimed at giving new scholarly definitions on culture or IC competences, skills or communication, but at sharing some insights of the authors about trans-cultural challenges faced during international conflict resolution operations by the military. This experience can be used during practical training in the preparation phase of officers and troops for deployment on a peace support operation when special attention should be paid to developing the proper attitudes and skills of servicemen for intercultural communication.

There is an increasing amount of research on quantity and quality of cultural knowledge of the military members and its integration to specific military systems, but the researchers underline that managing various cultural issues is restricted to "constrained directives rather than broad conceptual inquiries and systematic methods" in addressing military's cultural needs (Selmeski, 2007). The same author stresses that cross-cultural competence is not restricted to only one of the following 'ingredients': cultural awareness, additional language training, knowledge of International Relations, additional background on radical Islam, but it is rather a combination of knowledge/understanding, skills and behavior when dealing in an intercultural environment. For this researcher, cross-cultural competence for military professionals equals dealing successfully with members of the following groups: comrades (one's own unit), other military services and branches, allies, adversaries, non-combatants (incl. civilians, non-governmental organizations, and/or non-military government actors), politicians, and diverse communities.

When performing international operations for stabilization or post-conflict restoration, the positive outcomes of such operations depend on the degree of respect to cultural, religious and ethnic characteristics of the people(s) in the hot spot. In addition to maintaining excellent working relations with all the military allies and comrades irrespectively of their nationality and religion, it is of vital importance to gain the trust and respect of the local civilians and especially the interpreters, who are usually locals. The positive attitude of the local civilians is very often not only the key to the success of the mission, but can be life saving, because 
they can warn about increased activities of the adversary in the area or about preparations for an attack against the peacekeepers.

As an example we can give the work of a military advisor from an OMLT at the National Afghan Army.

A military advisor takes his professional duties seriously following the procedures, but despite his efforts to offer his military expertise to the Afghan partners, he cannot overcome his inner negativism towards the ethnicity of his partners. During the period of his deployment he cannot establish good working relations, so in the end he is ignored and unappreciated by the Afghan partners.

Personal characteristics can be a factor for the success or failure of intercultural interactions because they shape the way a person responds and reacts to different situations. Basically, every human subconsciously differentiates between friends and foes. This need is a result of the selfidentification and strive to socialize with those who are like you. Within the military context, past conflicts have been explained in terms of conflicting ideologies. However, some scholars consider political and social crises nowadays to be a result of the struggle to assert and maintain national and ethnic identities. As Gilroy (1997, p. 311) points out, "the term identity has become a significant marker in contemporary conflicts over cultural, ethnic, religious, 'racial' and national differences, where the idea of collective identity has emerged as an object of political thinking". Since our theoretical theses are based on examples from intercultural interactions in today's Afghanistan, it is necessary to explain the peculiarities of the Afghan identity which is an ethnic identity. Researchers (Wright, et al. 2010) underline ethnic identity as the most important factor shaping Afghanistan throughout history. This country is the home of six main ethnic groups (the main ethnic groups being Pashtuns and Tajiks) and many smaller ones that have been in complex relations of hostility and violence or alliances and unity in cases of an outside threat.

A difficult lesson in paying attention to ethnic differences was learnt by the Soviet High Command who initially included a large percentage of Uzbeks, Tadjiks, and Turkmen in the army at the beginning of Soviet-Afghan War. The High Command's hopes that Soviet soldiers of these nationalities would have a greater understanding of their kinsmen in Afghanistan were not fulfilled because the Pashtuns had historically always fought with the ethnic groups in the north, and the appearance of Uzbeks and Turkmen from a foreign land only strengthened the nationalities' discord (Marinov, 2017, p. 305).

The problem of cultural intolerance or rejection of cultural differences becomes even more significant when there is a need for communication and cooperation with local authorities, religious or nongovernmental organizations.

It is important to point out the indicative differences between civil and military culture because of the role of the military in a modern society: "Although civil and military cultures share many values in democracy, there must be significant differences between the cultures. For example, while our civil culture appropriately emphasizes liberty and individuality, military culture down-plays them and emphasizes values such as discipline and self-sacrifice that stem from the imperative of military effectiveness and success on the battlefield" (Center for Strategic and International Studies, 2000, p. 1). Thus, military organizations develop a culture into themselves, distinguished by an emphasis on hierarchy, tradition, rituals and customs, specific uniform and insignia. Military culture is defined as "the sum of its values, norms, philosophies, and traditions, which create the organizational climates 
within which our people in uniform function" in the Report on American Military Culture in the Twenty-First Century by the Center for Strategic and International Studies (2000). Amongst the values with the highest rate of significance for all members of the military personnel are self-sacrifice, discipline, obedience to legitimate authority, loyalty to nation, unit, and comrades.

Back in 1869, W. Windham described armed forces generally as "a class of men set apart from the general mass of the community, trained to particular uses, formed to peculiar notions, governed by peculiar laws, marked by peculiar distinctions" (Heinl, 1996, p. 14).

As the profession of arms has a long tradition with established laws and regulations derived from the nature of war, despite the various cultural differences in different countries throughout the human history there is an inherent 'civilian' belief that soldiers meet the exact precise moral, behavioral and physical standards and inherent nobility caused by the common conditions of service. They are considered to embody all that is best in the national character and are therefore respected by the civilian population.

On the other hand, military culture is affected by civil culture in many ways, as for example by the changes in technologies, by government policies, by common cultural traditions, etc.

\section{Military Values and Belief System}

All of the above mentioned characteristics of the military culture comprise some of the basics which govern and define military values and belief system.

A proof that the same basic military values are typical for the military personnel worldwide is the text of the military Oath of Allegiance in many armies (Georgieva, 2002). When swearing their oath, servicemen from different cultural, behavioral and historic background accept the values of loyalty, duty, respect, selfless service, honor, integrity and personal courage which are collectively referred to as army (military) ethic. Thus, each person enlisting in the US Armed Forces swears that they "will support and defend the Constitution of the United States against all enemies, foreign and domestic"; Bulgarian servicemen swear "to perform a faithful service for my nation, to abide the Constitution, state laws and military regulations; to implicitly obey the orders of my commanders and chief, to bravely defend integrity and independence of my motherland, and, if required, to sacrifice my life for her, for warrior dignity and to glorify my unit's flag". In accordance with the regulations of the Romanian Armed Forces (2000), the following oath is sworn: "I, (name), swear allegiance to my motherland, Romania. I swear to defend my country even if I have to sacrifice my life for that. I swear to obey the civilian laws and the military regulations. So help me God." In Afghanistan, establishment of professional army and police is also inseparable from swearing an oath. "The trainees place a hand on the certificate that bears both their name and Afghanistan's flag. They swear an oath - to never betray their people or their government, and if necessary, to sacrifice their lives for the freedom of their countrymen" (SHAPE, 2013). Being members of a specific social group with a specific set of values, traditions, activities, and everyday experiences, servicemen become members of their military subculture.

The above general characteristics of military culture have their peculiarities in Afghan society. First of all, the attitude of the civilian population towards the Afghan military is defined by the ethnic identity of the serviceman. Although representatives of different ethnic groups in Afghan Army do cooperate, the ethnic affiliations are still strong since, for example, a Pashtun major will select and assign Pashtuns as his 
guards. Secondly, the general attitude of both civilians and Afghan servicemen towards international peacekeepers and military advisors depends on the religion of the peacekeepers: if they are Muslim, they are considered closer, so the attitude is much friendlier towards Turkish military advisors, for instance, than towards Christian peacekeepers, who have to show respect and acceptance of the cultural customs and traditions of the locals if they want to gain respect in return.

Very often there are cases of disrespect of the Afghan populace towards international peacekeepers which is manifested through refusal to obey the instructions or commands of the peacekeepers. Such cases, however, should be treated differently: sometimes the local civilians who are with a very low social status (they lack basic education and have scarce, if any, financial income) simply do not understand the instructions (e.g. to give way to the convoy); other cases include purposeful opposition to the instructions. The military response is based on Force Escalation Procedures, but the procedures need to be followed cautiously and with careful consideration of each situation.

A car of a local Afghan has to be pulled over in order to give way to the military convoy. The peacekeeper makes the hand gesture "Stop!", but the driver does not obey. The peacekeeper follows the Force Escalation Procedures which define the next step: pointing a rifle towards the person. If this step does not change the behavior of the person, a warning shot follows. The final step is a direct shot in the person.

Typically, stressful military situations happen in the conditions of specific sand/dust fog and reduced visibility. However, it has been proven that locals will understand easier if instead of hand gestures or a weapon, pointing at them, a laser pointer is used: it is more clearly visible and somehow the message ("Stop!",
"Don't move!" or "Move there!") is communicated with less tension from the peacekeepers to the local civilians.

Very often the act of intercultural communication and sending a message (consciously or subconsciously) is performed non-verbally, i.e. by the way a person behaves. Special attention should be paid to body language: body movements (e.g. placing legs on the table, pointing to somebody with a finger, hands on the waist, etc.), gestures (hand shaking, hugging, nodding, etc.), and facial expressions (staring, smiling, eyes rolling, etc.) since they differ from culture to culture and can cause serious troubles and misunderstandings between militaries with different cultural background.

\section{Analysis of Situations with} Manifestation of Culture Differences and Inherited Cultural Behavior

Some of the main differences between the representatives of the western culture in general and Muslims/Afghans in particular, which are indicative of the importance of inherited cultural behavior, can be exemplified by the following situations:

\section{Situation 1:}

An international peacekeeper/military advisor wants to show friendliness towards his Afghan partner and pats him on the back/shoulder. After this act, the Afghan avoids meeting/communicating with that person.

The explanation for this "strange" from the western point of view response is that Afghan people consider this gesture insulting because patting somebody is an act of showing superiority, not friendliness.

\section{Situation 2:}

There are two men in military uniform walking around the military post hand in hand.

For representatives of western cultures, holding hands in public or in privacy is an act of intimacy or affection 
which is typical for people of the opposite sex or homosexuals. For Afghan people, however, both military and civilian men hold hands when they are close friends. It is not unusual for an Afghan serviceman to hold the hand of an international military advisor as a sign of trust and friendly relationship with him. Refusal by the western serviceman to accept the hand is considered alienating and results in loss of trust.

\section{Situation 3:}

Two men in military uniform meet for the first time during the day and they exchange kisses on the cheeks.

As with the previous situation, kisses between western men are culturally typical only for homosexuals. For Afghan and Muslim males, however, this is a cultural custom for expressing friendliness and respect. And again, refusal to exchange a kiss is considered by the locals an act of disrespect which in turn could hamper or prevent cooperation.

\section{Situation 4:}

An international peacekeeper/military advisor is in the middle of negotiations/ conversations with the locals when he spits in front of the main Afghan negotiator. The conversations are interrupted immediately. A couple of days later there is an ambush on the international troops who participated in the conversations.

Spitting in front of somebody is an extremely rude insult for the Afghans who respond accordingly: "If you do not respect me, I do not respect you either and do not want to communicate or cooperate with you".

\section{Situation 5:}

An international peacekeeper/military advisor is trying to communicate with an Afghan military partner. During the conversation, he wears his sunglasses. There is no positive result of the conversation, neither is cooperation achieved.

Afghan people consider avoiding eye contact insulting as for them it is an attempt to cover your feelings or emotions; for the Afghans sunglasses send the message which means "You have secrets, you are not honest, I cannot trust you." This cultural interpretation is in a serious conflict with US Army regulations that describe precisely the weather conditions in which wearing protective sunglasses is obligatory. Unfortunately, these regulations seriously hamper establishing mutual trust with the locals because their prescriptions do not take into account possible negative cultural interpretations.

If avoiding an eye contact between men is not acceptable, there is another unwritten but strict law in Afghan/Muslim culture: a man should not look straight into a woman even when she is completely covered in burqa. Staring at a Muslim woman is strictly forbidden. On the contrary, staring at a Christian woman by Muslims is not considered impolite or improper.

\section{Situation 6:}

An international peacekeeper/military advisor is trying to communicate with an Afghan person. He, however, does not notice that the Afghan person is sitting in such a way that the soles of his shoes are pointed towards the international peacekeeper. There is no positive result of the conversation.

If you can see the soles of the shoes of an Afghan, this is a sign of negligence and disrespect of the interlocutor. If you want to communicate your message to an Afghan person, you have to gain his respect first.

The conclusions from the situations which describe differences in the body language and the messages that are communicated across the cultures nonverbally are that in a military context interaction goes on many levels, including, but not restricted to, military hierarchy and subordination, religious differences and taboos, social background, ethnic preferences, etc. Consequently, presumed similarities as a result of shared common military values should not be taken for granted. On the contrary, military environment can highlight 
cultural differences and can lead to unpredictable miscommunication or even hostility if cultural differences are not approached cautiously.

The process of finding the common language for IC communication in our view is not about linguistic norms that have to be followed, but rather the focus has to be replaced on compromising and adapting, expressing openness and honesty, which guide the interlocutors towards mutually accommodating each other's needs and backgrounds. Experiencing cultural otherness is unavoidable, but the awareness of cultural differences helps shaping personal mindset in the way which is appropriate for its integration into the existing linguistic and cultural mindset.

The rule of thumb which can be followed in military interactions is that each human being responds positively and is open for communication if a positive attitude is expressed through a combination of empathy, thoughtfulness, and tolerance.

An Afghan officer is in severe pain as a result of an old injury. His Bulgarian partner from the OMLT gives him as a gift an electric appliance which helps him to reduce the pain. The next day the Afghan officer treats the Bulgarian officer with home-made sweets and cakes and passes the regards of his wife to him.

This simple story shows the power of human kindness and is emblematic for overcoming multi-layered cultural barriers since the gift sends a clear message to the Afghan officer: "I care about you, although I'm a stranger here and I'm superior to you in the military hierarchy". The consequence: the high religious and psychological barriers are broken and the proof is that an Afghan Muslim does the unthinkable from a Muslim point of view: he speaks about his wife and sends her regards to a Christian male. This story is also a proof a proof of Selmeski's suggestion that "blue" forces (i.e. friendly forces, Afghan forces in our case) "should be a primary focus of cultural learning as they represent the majority of cross-cultural contacts and therefore potential misunderstandings. Acknowledging the internal heterogeneity of armed forces may also reduce troops' tendency to see the world in stark and counter-productive dichotomies of "us versus them" (Selmeski, 2007). This story also proves the statement that Intercultural Communication is "a multidisciplinary field which has as much relevance in trying to understand - and overcome - the barriers of communication between different people and different groups within the same country" (Singer, 1998).

A good example of how intercultural communication can be facilitated when there is a shift of the focus from cultural differences to common traditions is the custom of drinking tea and the meanings which can be attributed to it. This custom demonstrates complexity and value of everyday interactions. Similarly to the customs of drinking tea in Russia, Britain, China, Japan, Turkey, Egypt, Morocco and some other countries, it is time for socializing. In the military context, drinking tea for the Afghan military is a ritual at the beginning of the work day. If an international military member is invited to tea, this invitation is a symbol of good attitude, friendliness and good will for cooperation. If you refuse the invitation, it will be considered an insult. On the contrary, if you are not invited to tea by your Afghan partner, this means that you are not trusted and signifies a serious problem in your relations with him. Being time for socializing, tea drinking requires a certain mode of relaxed communication. The best way to socialize during tea time is to politely ask about the family and kids (not about the wife!) of your Afghan counterpart, to talk about the weather and to answer similar questions. If you apply the direct approach of western cultures and raise the work issue at the beginning of the tea ritual, it is considered bad manners and 
the response is that you would probably never be invited to tea again which in turn would put an end to your efforts for establishing cooperation. Thus, this simple custom can have either very positive or very negative professional consequences depending on the level of your adaptability and readiness to focus on what is common for "us" rather than to stress and complain about the differences between "us" and "them".

\section{Conclusion}

There is no a prescription or a universal procedure of the exact steps that the military should undertake or follow in their everyday interactions in order to accomplish their mission successfully when participating in international peace support operations. What is proven to be working, however, is that the foundation of the mission's success is composed of honesty, respect, openness and good will in the process of communication with both allies and local partners, authorities, and civilians.

\section{REFERENCES}

Center for Strategic and International Studies. (2000). American Military Culture in the Twenty-First Century, available at: https://www.csis.org/analysis/american-military-culturetwenty-first-century, accessed at: 8.08.2017.

Georgieva, V. (2002). Military Oath of Allegiance - the Bridge between Cultural Differences of the Military Personnel Worldwide, Collection of Scientific Papers at Naval Academy, Varna, Bulgaria, Vol. 25, 75-80.

Gilroy, P. (1997). Diaspora and the Detours of Identity, In Woodward, K. Identity and Difference, SAGE Publications, UK.

Heinl, R. (1996). Dictionary of Military and Naval Quotations, USA: Naval Institute Press, 14.

Marinov, P. (2017). Modern Challenges of the Counterterrorism System Management, Sofia, Bulgaria: East-West.

North Atlantic Treaty Organization. (2013). NATO Glossary of Terms and Definitions AAP-06. available at: http://www.dtic.mil/doctrine/doctrine/other/aap6.pdf, accessed at: 8.08.2017.

Supreme Headquarters Allied Powers Europe - SHAPE. (2013). New Afghan Police Swear Allegiance, available at: http://www.shape.nato.int/new-afghan-police-swearallegiance, accessed at: 7.07.2016.

Porter, R. E. \& Samovar, L. A. (1994). An Introduction to Intercultural Communication, In Reader, A. Intercultural communication, Belmont, CA, USA: Wadsworth Publishing Company.

Romanian Armed Forces. (2000). Regulation of the Interior Service, Annex 1, Art. 6, p. 87, Bucharest: Author. 
Russian General Staff. (2002). The Soviet-Afghan War. How a Superpower Fought and Lost, translated and edited by Graw, L. W. \& Gress, M. A., Kansas, USA: University Press of Kansas.

Selmeski, B. (2007). Military Cross-Cultural Competence: Core Concepts and Individual Development, Royal Military College of Canada, Centre for Security, Armed Forces \& Society. Occasional Paper Series - Number 1.

Singer, M. (1998). Perception and Identity in Intercultural Communication, Yarmouth, ME, USA: Intercultural Press, Inc.

Watson, J. (2010). Language and Culture Training: Separate Paths?, Military Review \# 2, Fort Leavenworth, Kansas, USA: US Army Combined Arms Center.

Wright, D. P., Bird, J. R., Clay, S. E., Connors, P. W., Farquhar, S. C., Garcia, L. C. \& Van Way, D. F. (2010). A Different Kind of War, USA: Books Express Publishing. 